\title{
Modeling, Investigation, and Mitigation of AC Losses in IPM Machines with Hairpin Windings for EV Applications
}

\author{
Mingyu Choi (1) and Gilsu Choi * \\ Department of Electrical Engineering, Inha University, Incheon 22212, Korea; mingyu5832@inha.edu \\ * Correspondence: gchoi@inha.ac.kr
}

Citation: Choi, M.; Choi, G. Modeling, Investigation, and Mitigation of AC Losses in IPM Machines with Hairpin Windings for EV Applications. Energies 2021, 14, 8034. https://doi.org/10.3390/ en14238034

Academic Editors: Renato Rizzo and Luigi Pio Di Noia

Received: 24 October 2021 Accepted: 22 November 2021 Published: 1 December 2021

Publisher's Note: MDPI stays neutral with regard to jurisdictional claims in published maps and institutional affiliations.

Copyright: (c) 2021 by the authors. Licensee MDPI, Basel, Switzerland. This article is an open access article distributed under the terms and conditions of the Creative Commons Attribution (CC BY) license (https:// creativecommons.org/licenses/by/ $4.0 /)$.

\begin{abstract}
Interior permanent magnet (IPM) machines with hairpin windings have attracted significant attention in EV applications owing to their low DC resistance and excellent thermal capabilities. In this paper, we present a comprehensive investigation of AC winding losses in IPM machines for traction applications, including analytical modeling, the influence of design parameters, and finite element (FE) verification. The proposed analytical model can predict the trends in AC winding losses for any number of bar conductors and slot/pole combinations. The results of the parametric study, obtained via the analytical model, are presented to examine the effects of key design parameters, such as conductor width and height, phase arrangement, and slot-per-pole-per-phase (SPP). To incorporate more practical issues into the analysis of IPM machines with hairpin windings, extensive FE simulations were conducted. The results indicated that the AC winding losses decrease with an increasing number of conductor layers and phases inside the slot.
\end{abstract}

Keywords: electric vehicle (EV); AC winding losses; interior permanent magnet synchronous machine (IPMSM); bar-wound windings; one-dimensional (1D) analytical model; finite element analysis (FEA); loss per torque density (LPTD)

\section{Introduction}

In the past decade, there have been significant technical advances in the electric vehicle (EV) market to satisfy global environmental regulations. Furthermore, the demand for improved energy efficiency [1] has increased. In particular, an electric drivetrain, which typically consists of an inverter, a traction machine, and a reduction gear, is considered a key technology for extending the driving range and improving fuel economy. Among the different types of traction machines, interior permanent magnet synchronous machines (IPMSMs) are the most popular in the market owing to their excellent torque density and efficiency and their wide constant power speed ratio (CPSR) [2]. Although an interior permanent magnet (IPM) machine exhibits the highest efficiency when compared to any other type of machine, efforts are underway to further increase the efficiency of IPM machines by advancing machine topologies, materials, and manufacturing techniques.

Recently, hairpin windings have been adopted by many EV manufacturers to reduce fuel consumption over standard driving cycles, as well as production lead time. This is because hairpin windings typically exhibit a higher copper fill factor, shorter end windings, lower DC resistance, higher torque density, excellent thermal performance, and a highly automated manufacturing process [3-6]. Unlike conventional random windings, hairpin winding allows precise placement of each conductor within a slot and a consistent arrangement of the end windings. Given these features, hairpin windings are highly effective in oil cooling systems. [7,8]. Owing to more efficient cooling, the machine's current density increases significantly, resulting in a higher torque density.

A challenge involved in designing machines with hairpin winding involves vulnerability to skin effects and proximity effects due to its relatively large cross-sectional area. Figure 1 shows contour plots, predicted via finite element (FE) analysis, to present 


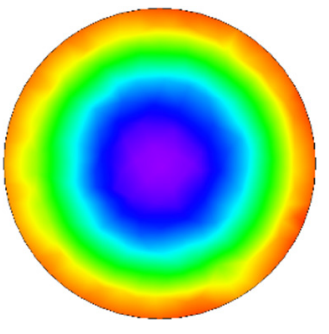

(a)

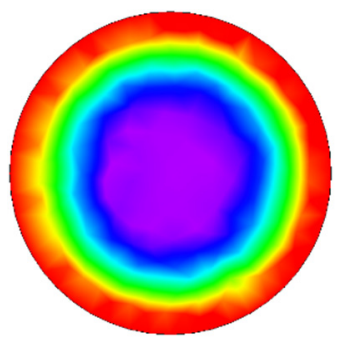

(b)
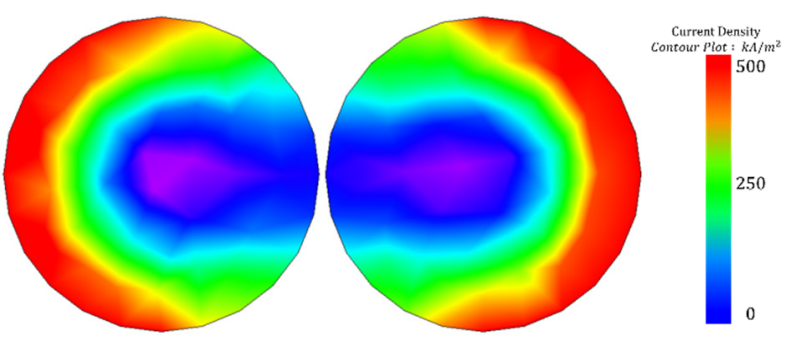

(c)

Figure 1. Current density distribution within a conductor(s) as a function of skin effects and proximity effects: (a) Single conductor at $20 \mathrm{Apk}, 2 \mathrm{kHz}$; (b) Single conductor at $20 \mathrm{Apk}, 4 \mathrm{kHz}$; (c) Two adjacent conductors at $20 \mathrm{Apk}, 2 \mathrm{kHz}$.

The following subsections provide a thorough literature review of selected techniques for mitigating AC winding losses in IPM machines with hairpin windings.

\subsection{Number of Conductor Layers}

An effective technique for reducing AC losses involves increasing the number of bar conductor layers within a slot. As the number of conductor layers increases, the crosssection of each conductor decreases, and the impact of the skin and proximity effects decreases, as shown in Figure 2. For example, AC winding losses at high frequencies can be reduced by changing the number of conductor layers from four to six, as reported in $[14,15]$. In $[4,16]$, the current density and AC winding losses within a slot were calculated using a one-dimensional (1D) analytical model as a function of the number of conductor layers. The results showed that the AC winding losses are proportional to the number of conductor layers. Unfortunately, no further analysis was conducted to investigate the effect of the number of layers on other aspects, such as the copper fill factor and manufacturing complexity.

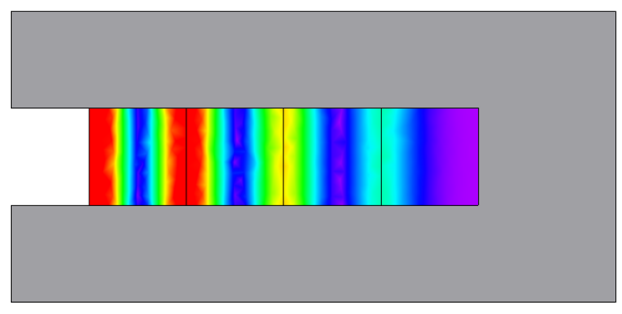

(a)

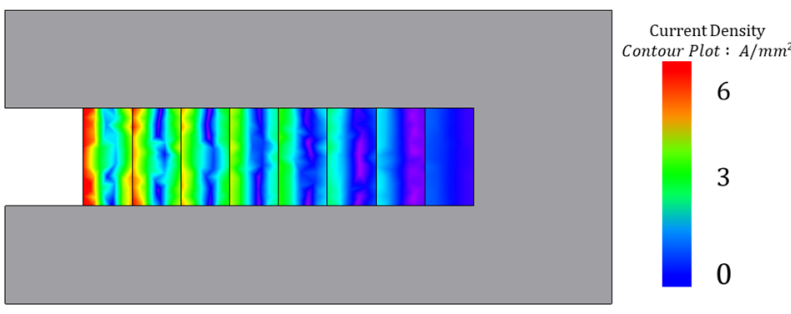

(b)

Figure 2. Slot-level current density contour plot (excitation condition: 80 Apk/conductor at $2 \mathrm{kHz}$ ): (a) 4 conductors; (b) 8 conductors.

In [17], analytical results using a 1D analytical model were compared with FEcalculated results. The comparison showed that the two results are in decent agreement. According to the FE-predicted results in [18], the optimal number of layers can vary based on the driving cycle and operating point of the machine, and an increasing number of layers does not always lead to lower losses. 


\subsection{Conductor Geometry}

The conductor geometry and aspect ratio can significantly affect the AC winding losses. The average effect of the bar winding geometry on AC winding losses was analyzed using analysis of variance (ANOVA) [19]. The results indicated that the calculated AC losses are sensitive to the height of the bar conductor. The impact of the aspect ratio of the bar conductors was analyzed using FE analysis, and the results showed that the optimal conductor size for minimum AC losses is dependent on the excitation frequency [18].

A two-dimensional (2D) analytical model was used to calculate the AC winding losses as a function of conductor width and height [20]. The results showed highly similar trends to those in [18]. The results presented in $[18,20]$ reveal that there does not exist a specific conductor width and height that can guarantee minimum winding losses over the entire operating region. The optimal conductor shape of a traction machine can be determined by calculating the average losses throughout the driving cycle.

\subsection{Asymmetric Conductor Arrangement}

In general, large $\mathrm{AC}$ winding losses occur in conductors near the air gap owing to the fringing effect [12,21]. To solve this problem, [22] proposed a method to reduce the total losses by reducing the cross-sectional area of the conductor located close to the slot opening, as shown in Figure 3. In addition, the FE-predicted results presented in [22] showed that the application of an asymmetric winding layout can aid in improving machine performance in terms of $\mathrm{AC}$ winding losses, efficiency, temperature, and continuous torque characteristics.
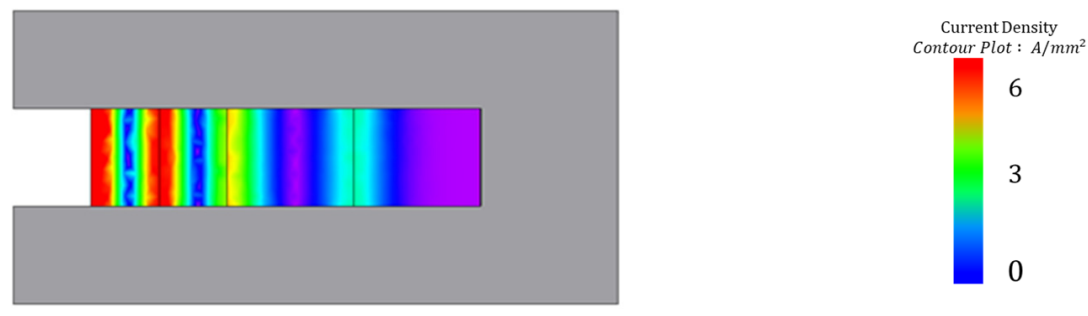

Figure 3. Slot-level current density contour plot of asymmetric four-layer conductors ( $80 \mathrm{Apk}, 2 \mathrm{kHz}$ ).

A key constraint in this study involves maintaining the copper fill factor at a constant value while the cross-sectional area of each conductor is varied in an asymmetric manner. However, the average current density distribution is no longer uniform for asymmetric bar conductors in the slot. Therefore, it is extremely important to avoid exceeding the specified current density limits.

\subsection{Winding Phase Arrangement}

The winding phase arrangement is another important factor that affects the $\mathrm{AC}$ winding losses in traction machines. The current density distribution and resulting AC losses in the stator windings can vary significantly with the phase arrangement. In [23], analytical and FE results were provided to analyze the effect of phase arrangements on the current density distribution and winding resistance inside a single slot. The results indicated that the winding resistance increases when there is only one phase inside the slot (single-phase arrangement as depicted in Figure 4a), and decreases when two different phases are placed in the same slot (two-phase arrangement as depicted in Figure 4b). 


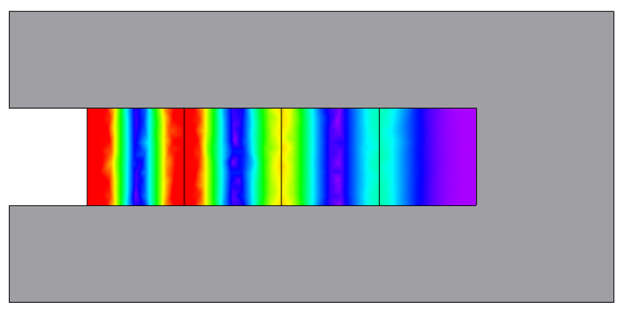

(a)

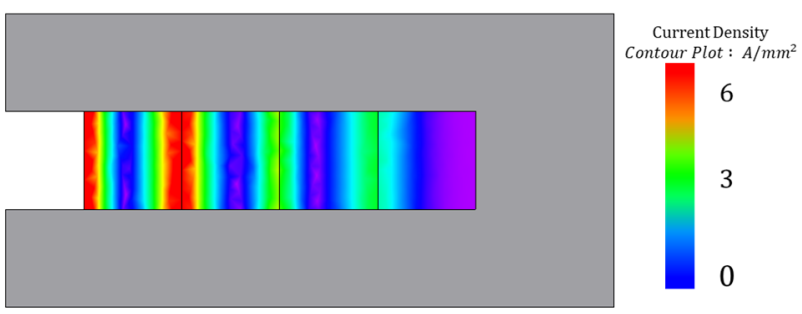

(b)

Figure 4. Slot-level current density contour plot of four-layer conductors with two types of phase arrangements (80 Apk, $2 \mathrm{kHz}$ ): (a) Phase arrangement: AAAA; (b) Phase arrangement: ABAB.

A previous study analyzed the impact of the phase arrangement on $\mathrm{AC}$ winding losses in a single slot using a 2D analytical model [20]. The results were similar to those in [23], wherein the worst-case AC losses occur when the slot contains only single-phase coils, and the losses decrease when the slot contains multiphase coils. Furthermore, the effect of the phase arrangement on the AC losses of the entire machine was investigated using a 2D analytical model [24]. The results are consistent with those presented in the literature.

Moreover, the change in phase arrangement can lead to a reduction in the winding factor, and thereby in the average torque of the machine. Unfortunately, to date, there is a paucity of studies on establishing a comprehensive understanding of $\mathrm{AC}$ winding losses in IPM machines designed for traction applications. Table 1 summarizes a literature review of AC losses in electric machines.

Table 1. Summary of literature review.

\begin{tabular}{cc}
\hline Subject & Reference(s) \\
\hline Number of Conductor Layers & {$[4,14-18,20,25-27]$} \\
Conductor Shape (height \& width) & {$[18-20,25]$} \\
1D Analytical Model & {$[3,16,16,23,25-29]$} \\
1D Analytical Model (Single-phase) vs. FEA & {$[4,16,17,26]$} \\
1D Analytical Model (Two-phase) vs. FEA & {$[23,25,29]$} \\
2D Analytical Model & {$[20,24,25]$} \\
Random Windings vs. Hairpin Windings & {$[3]$} \\
Temperature Variation by AC Losses & {$[26]$} \\
Asymmetric Bar Winding & {$[22]$} \\
Phase Arrangement & {$[20,23-25]$} \\
Proximity Effect & {$[11-13]$} \\
Slot Opening Effect & {$[17,19]$} \\
Conductor Shape \& Disposition & {$[13]$} \\
Coil Split & {$[9]$} \\
Winding Transposition & {$[11]$} \\
Magnetic Wedge & {$[30,31]$} \\
Impact of SPP & {$[17]$} \\
\hline
\end{tabular}

In this study, we aim to provide a detailed and comprehensive investigation of AC winding losses in IPM machines for EV applications, including winding configurations and dimensions, analytical and numerical methods, manufacturing aspects, and loss mitigation techniques. The major contributions of this study are as follows:

- To investigate the effect of the number of layers, slots per pole per phase (SPP), and the phase arrangement on $\mathrm{AC}$ winding losses using a $1 \mathrm{D}$ analytical model and verification via FE analysis;

- To extend the winding loss analysis to the motor level and investigate the impact of key operating points of EV traction machines;

- To provide a comprehensive comparative analysis of AC winding losses in several IPM machines with different winding configurations under practical design specifications and constraints. 
The remainder of this paper is organized as follows. In Section 2, we introduce a 1D analytical model for calculating the current density and AC losses. The analysis results obtained via the 1D model were verified using FE analysis. In Section 3, practical IPM machines are designed using FE analysis and used to investigate the effect of the number of conductor layers, SPP, and phase arrangement on each AC loss at the motor level. Section 4 presents the AC loss results for baseline IPM traction machines as a function of the number of layers, SPP, and phase arrangement for key operating points that can represent standard driving cycles.

\section{1D Analytical Model}

\subsection{Theory}

Owing to the skin and proximity effects, a non-uniform winding current distribution occurs inside the conductor at high frequencies [32]. Unlike random windings, the nonuniform current distribution in hairpin windings cannot be neglected because of the large cross-sectional area of the bar conductors. In this study, a 1D analytical model based on Maxwell's equations is used to consider the interaction between the nonuniform current distribution and magnetic field distribution inside the slot area [25,32].

Figure 5 shows the slot geometry used in the 1D modeling without including the insulation thickness and slot opening effect. Given that the 1D model assumes no field variation along the $y$-axis, the effects of winding insulation and fringing fields are not included in the analysis. However, these effects should not be ignored for practical purposes. Therefore, they are investigated via FE analysis in later sections.

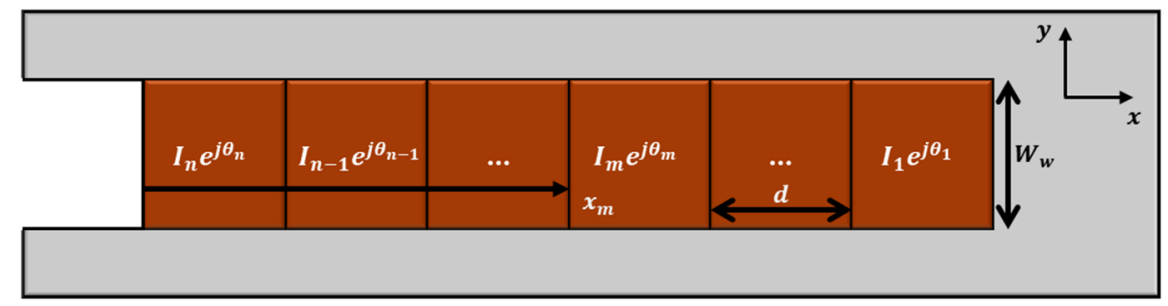

Figure 5. Slot geometry used in the 1D analytical model.

Several key assumptions used to simplify the 1D analytical model are as follows:

- Pure sinusoidal currents flowing through the conductors

- A magneto-quasistatic (MQS) field distribution

- Negligible insulation thickness

- $\quad$ Slots are fully opened

- Lossless core material with infinite permeability

- $\quad$ Only the $z$-axis component of the magnetic field and $y$-axis component of the magnetic field intensity exist

The three fundamental Maxwell's equations that were used for modeling the distribution of the current density and magnetic field in the conductor region are as follows:

$$
\begin{gathered}
\nabla \times \boldsymbol{E}=-\frac{\partial \mu \boldsymbol{H}}{\partial t} \\
\nabla \times \boldsymbol{H}=\boldsymbol{J} \\
\nabla \cdot \boldsymbol{B}=0
\end{gathered}
$$

where $\mu$ denotes the relative permeability of the conductor material, $\boldsymbol{E}$ denotes the electric field strength, $\boldsymbol{J}$ denotes the current density, $\boldsymbol{H}$ denotes the magnetic field intensity, and $\boldsymbol{B}$ denotes the magnetic flux density. It should be noted that the displacement current was ignored in the conductor region. 
Applying Ohm's law yields the following equation:

$$
J=\sigma E
$$

where $\sigma$ is the conductivity of the conductor material.

Since the magnetic field intensity has the $y$-component only for this 1D problem, substituting (1) into (2) after taking the curl of both sides of (2) yields:

$$
\frac{1}{\mu \sigma} \nabla^{2} H_{y}=\frac{\partial H_{y}}{\partial t}
$$

And the magnetic vector potential has only the $z$-component, the following expression is derived as follows:

$$
H_{y}=-\frac{1}{\mu} \frac{\partial A_{z}}{\partial x}
$$

Let the $z$-component of magnetic vector potential $A_{z}$ for the $m^{\text {th }}$ conductor to be:

$$
A_{z, m}=M_{m} e^{-\gamma\left(x-x_{m}\right)}+N_{m} e^{+\gamma\left(x-x_{m}\right)}
$$

where $\gamma=\sqrt{j \omega \mu \sigma}, \omega$ is the angular frequency of the time-varying field, and $M$ and $N$ are the coefficients to be calculated.

Then, the magnetic fields of the $(m-1)^{t h}$ conductor and the $m^{\text {th }}$ conductor can be expressed as follows:

$$
\begin{gathered}
H_{y, m-1}=-\frac{\gamma}{\mu}\left[-M_{m-1} e^{-\gamma\left(x-x_{m-1}\right)}+N_{m-1} e^{+\gamma\left(x-x_{m-1}\right)}\right] \\
H_{y, m}=-\frac{\gamma}{\mu}\left[-M_{m} e^{-\gamma\left(x-x_{m}\right)}+N_{m} e^{+\gamma\left(x-x_{m}\right)}\right]
\end{gathered}
$$

where $x$ is the distance from the edge of the leftmost conductor (see Figure 5).

By applying the boundary condition between the slot and the conductors in Figure 5, the following expression is derived:

$$
M_{1} e^{-\gamma d}-N_{1} e^{+\gamma d}=0
$$

By applying (10) to the $m^{\text {th }}$ and $m-1^{\text {th }}$ conductors, the following relationship is obtained as follows:

$$
M_{m-1}-N_{m-1}=M_{m} e^{-\gamma d}-N_{m} e^{+\gamma d}
$$

where $d$ is the conductor height.

The net current constraint of each conductor is satisfied by Ampere's law, which can be expressed as in the following:

$$
\frac{\gamma}{\mu} W_{w}\left[M_{m}\left(1-e^{-\gamma d}\right)-N_{m}\left(1-e^{+\gamma d}\right)\right]=-I_{m} e^{j \theta_{m}}
$$

where $W_{w}$ is the conductor width, $I$ is the current magnitude, $\theta$ is the current phase angle.

The coefficients $M_{m}$ and $N_{m}$ satisfying the above boundary condition and net current constraint are expressed as follows:

$$
\begin{aligned}
& M_{m}=-\frac{\mu e^{\frac{\gamma d}{2}}}{2 \gamma W_{w}}\left[\frac{e^{\frac{\gamma d}{2}} I_{m} e^{j \theta_{m}}}{\sinh (\gamma d)}+\sum_{i=1}^{m-1} \frac{I_{i} e^{j \theta_{i}}}{\cosh \left(\frac{\gamma d}{2}\right)}\right] \\
& N_{m}=\frac{\mu e^{-\frac{\gamma d}{2}}}{2 \gamma W_{w}}\left[-\frac{e^{-\frac{\gamma d}{2}} I_{m} e^{j \theta_{m}}}{\sinh (\gamma d)}+\sum_{i=1}^{m-1} \frac{I_{i} e^{j \theta_{i}}}{\cosh \left(\frac{\gamma d}{2}\right)}\right]
\end{aligned}
$$


Substituting (13) and (14) into (7), the following expression is derived as follows:

$$
A_{z, m}=-\frac{\mu e^{\frac{\gamma d}{2}}}{2 \gamma W_{w}}\left[\frac{e^{\frac{\gamma d}{2}} I_{m} e^{j \theta_{m}}}{\sinh (\gamma d)}+\sum_{i=1}^{m-1} \frac{I_{i} e^{j \theta_{i}}}{\cosh \left(\frac{\gamma d}{2}\right)}\right] e^{-\gamma\left(x-x_{m}\right)}+\frac{\mu e^{-\frac{\gamma d}{2}}}{2 \gamma W_{w}}\left[-\frac{e^{-\frac{\gamma d}{2}} I_{m} e^{j \theta_{m}}}{\sinh (\gamma d)}+\sum_{i=1}^{m-1} \frac{I_{i} e^{j \theta_{i}}}{\cosh \left(\frac{\gamma d}{2}\right)}\right] e^{+\gamma\left(x-x_{m}\right)}
$$

By substituting (6) \& (7) into (2), the current density of the $m^{\text {th }}$ conductor can be found as in the following:

$$
J_{z}=\frac{\gamma^{2}}{\mu}\left[-\frac{\mu e^{\frac{\gamma d}{2}}}{2 \gamma W_{w}}\left\{\frac{e^{\frac{\gamma d}{2}} I_{m} e^{j m_{m}}}{\sinh (\gamma d)}+\sum_{i=1}^{m-1} \frac{I_{i} e^{j \theta_{i}}}{\cosh \left(\frac{\gamma d}{2}\right)}\right\} e^{-\gamma\left(x-x_{m}\right)}+\frac{\mu e^{-\frac{\gamma d}{2}}}{2 \gamma W_{w v}}\left\{-\frac{e^{-\frac{\gamma d}{2}} I_{m} e^{j \theta_{m}}}{\sinh (\gamma d)}+\sum_{i=1}^{m-1} \frac{I_{i} e^{j \theta_{i}}}{\cosh \left(\frac{\gamma d}{2}\right)}\right\} e^{+\gamma\left(x-x_{m}\right)}\right]
$$

Finally, AC losses $P_{A C}$ in the $m^{\text {th }}$ conductor is derived as follows:

$$
P_{A C}=\frac{W_{w} l_{e}}{\sigma_{c}} \int_{0}^{d} J_{z}^{2} d x
$$

where $l_{e}$ is the axial (z-axis) length of the 1D model.

\subsection{Slot-Level Analysis: Comparison of Current Density Using 1D Model}

In this section, the slot-level current density distribution, calculated via the 1D model, is compared with the FE-predicted results to verify the accuracy of the model. In addition, the effects of the phase arrangement and conductor geometry on the current density distribution are investigated. The FE analysis is conducted using JMAG-Designer software.

Figure 6 presents a comparison of the analytical and FE results in terms of the current density distribution inside a single slot with eight conductors. A comparison of results in Figure $6 \mathrm{a}, \mathrm{b}$ reveals that the $\mathrm{AC}$ losses of the eight conductors, in which the A and $\mathrm{B}$ phases are alternately arranged (ABABABAB), were smaller than those of the full pitch arrangement (AAAAAAAA). When compared with the full-pitch configuration results, the current density of the alternating phase arrangement was lower by a factor of 2 . This indicates that AC losses can vary significantly according to the configuration of the phase arrangement under the same excitation conditions. Overall, given the assumptions, there was an excellent agreement between the analytical and FE results. Hence, the proposed 1D model can be used for different types of conductor layers and phase arrangements without compromising accuracy.

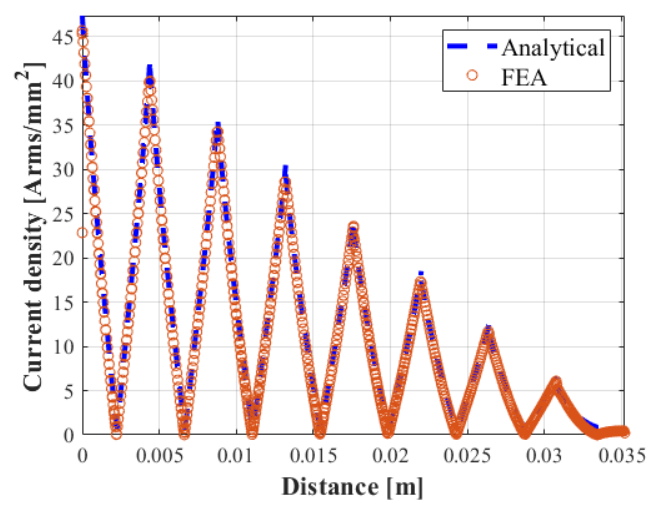

(a)

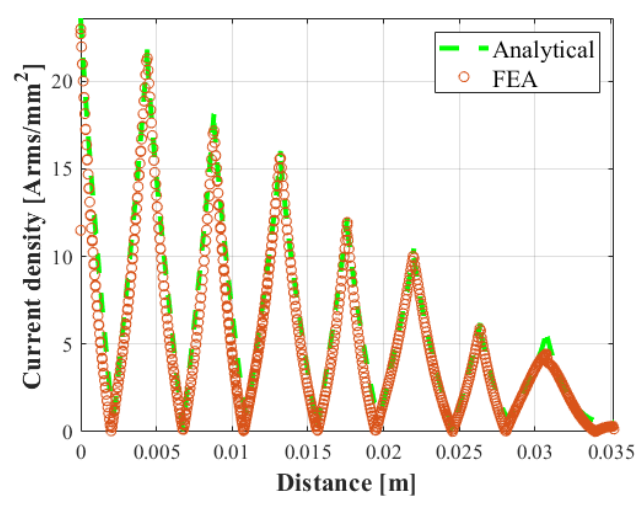

(b)

Figure 6. Comparison of analytical and FE results in terms of current density. (a) Phase arrangement: AAAAAAAA at 40 Apk, 2 kHz, (b) Phase arrangement: ABABABAB at 40 Apk, 2 kHz.

Many previous 1D analytical models assume that the current $I_{m}$ flowing inside the $m^{\text {th }}$ conductor is always the same, which limits the model's applications when analyzing problems with multi-phase slots and short pitch windings. However, the 1D ana- 
lytical model introduced in this paper is able to analyze the AC losses in a slot with multi-phase windings when different current magnitudes and phases are applied to each individual conductor.

Figure 7 illustrates the slot leakage flux flowing through a slot from one tooth to another [33]. As shown in Figure 7, the conductor height $d$ determines the area through which the leakage flux passes. Thus, the AC losses are highly sensitive to changes in the conductor height. However, the conductor width $W_{w}$ affects the circumferential path of the leakage flux and has a relatively low impact on AC losses. This parameter mainly affects the $\mathrm{DC}$ resistance of the winding.

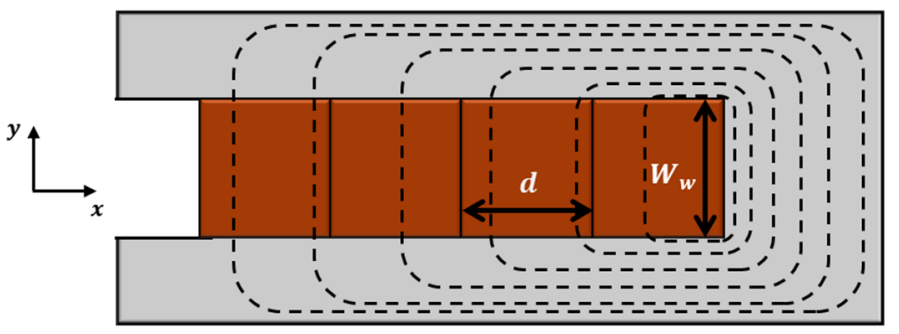

Figure 7. Slot leakage flux lines.

Figure $8 \mathrm{a}, \mathrm{b}$ show the total copper losses inside a single slot as a function of the conductor width and height, respectively. As shown in Figure 8a, the total copper losses monotonically decrease as the conductor width, $W_{w}$, increases. Conversely, Figure $8 \mathrm{~b}$ shows that the losses decrease to a certain value of conductor height and then start to increase rapidly as the conductor height continues to increase. This is because the conductor height $d$ affects the skin depth of the conductor. According to [34], the optimal ratio of conductor height to skin depth for minimal loss can be derived as follows:

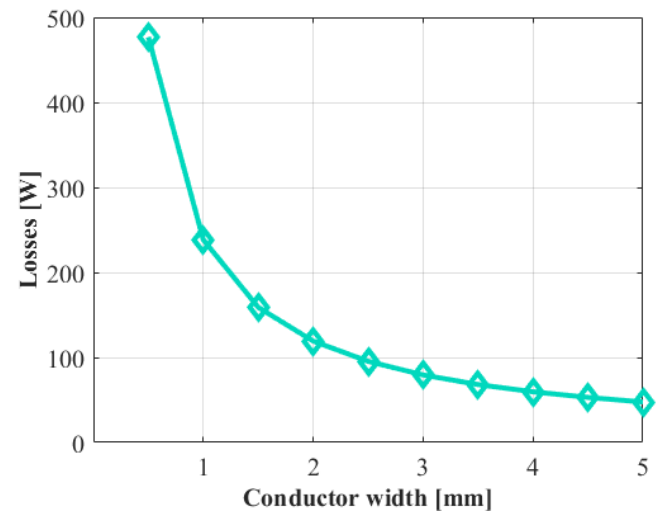

(a)

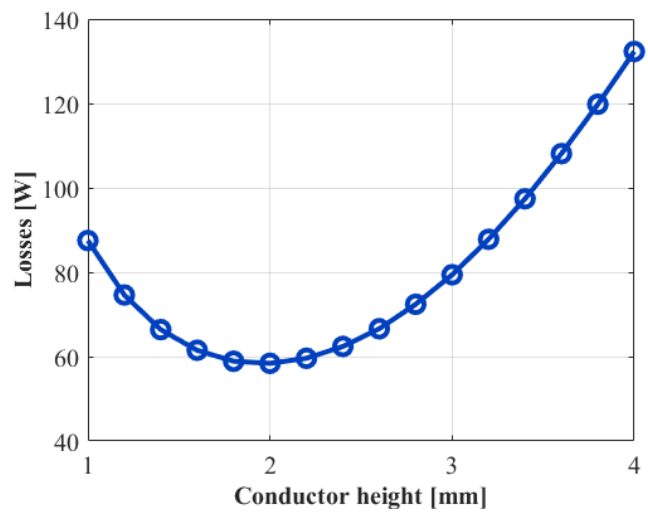

(b)

Figure 8. Copper losses inside a single slot with four conductors (excitation condition: $200 \mathrm{Apk} /$ conductor at $500 \mathrm{~Hz}$ : (a) Copper losses vs. width, $d=3 \mathrm{~mm}$; (b) Copper losses vs. height, $W_{w}=3 \mathrm{~mm}$.

$$
\delta_{\text {optimal }}=\left(\frac{15}{5 \cdot(\text { number of layers })^{2}-1}\right)^{0.25}
$$

The calculated optimal conductor height for the model used in Figure $8 \mathrm{~b}$ is $1.92 \mathrm{~mm}$, which is very close to the results shown in Figure $8 \mathrm{~b}$.

Section 2.3 presents a more detailed analysis of the remaining key design parameters. 


\subsection{Motor-Level Analysis: Effects of Design Parameters}

To calculate the total copper losses of the entire stator windings, the 1D analytical model was extended to the motor level by connecting the conductors within a single slot to form a three-phase stator winding. The analytical results were verified by comparing them with the FE-calculated results. To ensure a fair comparison, some of the assumptions introduced in Section 2.3 (i.e., no insulation, open slots, and sinusoidal current) were applied to FE modeling. The main differences between the analytical model and FE model include the effects of the core saturation, rotor MMF, and rotor rotation. Given that the focus is on the stator-related design parameters, the same rotor structure is applied to all designs, as shown in Figure 9.

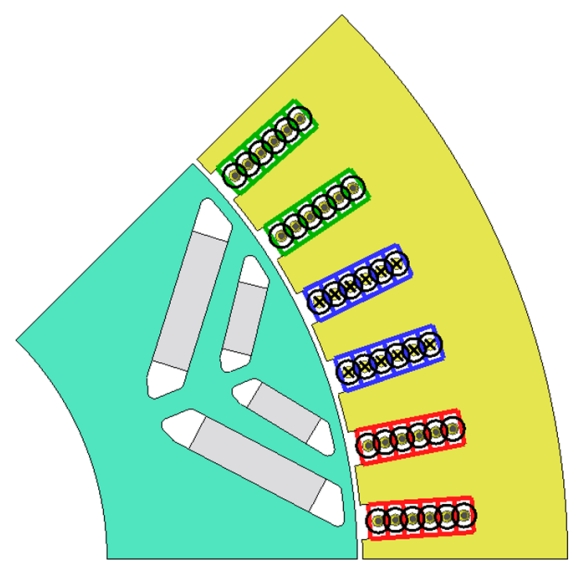

(a)

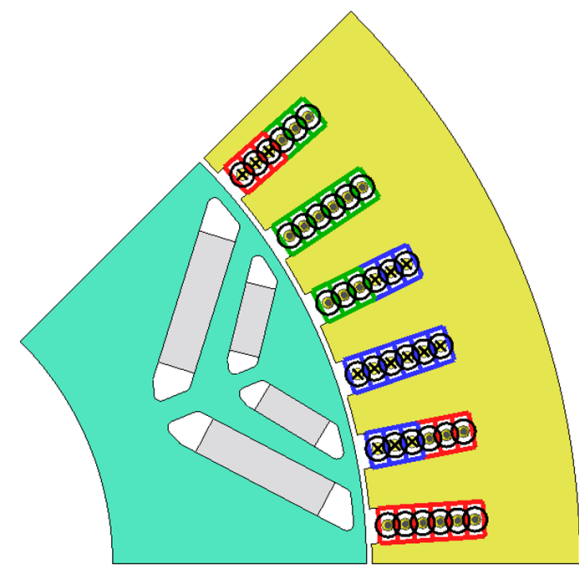

(b)

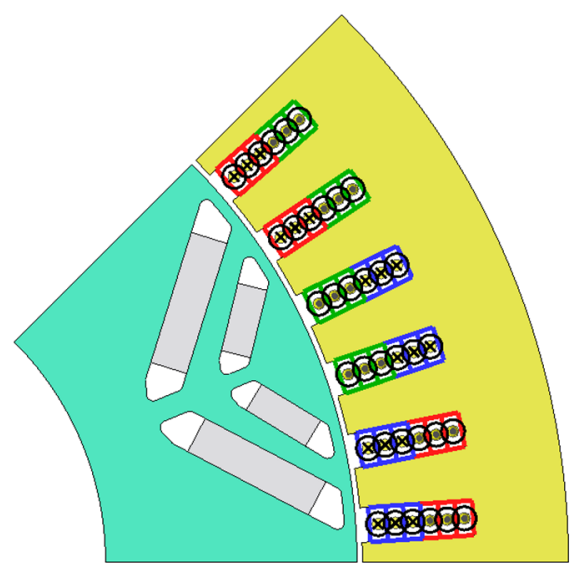

(c)

Figure 9. Three winding layout configurations: (a) FP winding layout with single-phase conductors in each slot; (b) SP-A winding layout with single-phase and two-phase conductors in each slot; (c) SP-B winding layout with only two-phase conductors in each slot.

To compare the loss characteristics of the various winding configurations shown in Table 2, the following constraints are considered for analytical and FE models:

- Constant stator MMF (i.e., turns*current)

- Stator inner radius: $75.4 \mathrm{~mm}$

- Peak current density at 400 Arms: 25 Arms $/ \mathrm{mm}^{2}$

- $\quad$ Back yoke thickness: $12.5 \mathrm{~mm}$.

Table 2. Summary of key design parameters for baseline machines.

\begin{tabular}{cc}
\hline Parameter & Values \\
\hline SPP & $2,3,4$ \\
Number of Layer & $4,6,8$ \\
Phase Arrangement & AAAA, AABB, ABAB \\
Winding Layout & Full Pitch, Short Pitch A, Short Pitch B \\
\hline
\end{tabular}

The impact of SPP, number of conductor layers, phase arrangement, and winding layout on the AC losses is analyzed in this subsection. To examine the effect of changes in the number of slots and conductor shape on AC losses, SPP values were varied from 2 to 4 . In addition, three different winding layout configurations were considered: full pitch (FP), short pitch A (SP-A), and short pitch B (SP-B). As shown in Figure 9, SP-A has slots filled with single-phase and two-phase conductors. Conversely, SP-B has only two-phase conductors in each slot. By considering the aforementioned conditions, the effects of conductor width and height, coil pitch, and phase configuration on the total 
AC losses can be investigated by conducting a series of $1 \mathrm{D}$ and FE analyses based on the information shown in Table 2.

Figure 10 compares the AC losses of each SPP based on the key parameters summarized in Table 2 using the FE analysis (bars with light colors) and 1D analytical model (bars with dark colors), respectively. As expected, the results are consistent with the findings from Section 2. Specifically, as the number of conductors and phases inside each slot increases, AC losses decrease. Closer inspection reveals that the optimal frequency at which the minimum AC losses occur increases as the number of conductor layers increases. Specifically, at excitation frequencies above $170 \mathrm{~Hz}$, the lowest AC losses occur in models with eight conductors per slot.

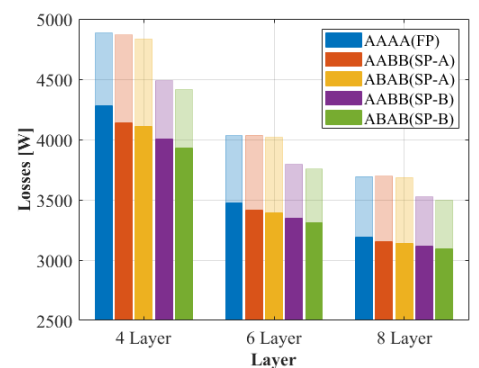

(a)

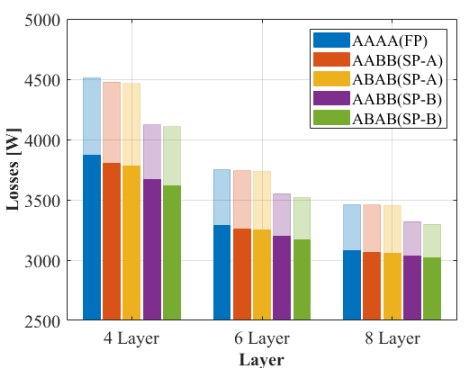

(b)

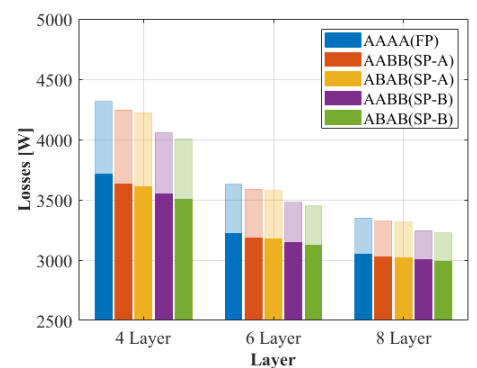

(c)

Figure 10. Comparison of $A C$ losses for three SPP values. In the loss group of each layer, phase arrangements are in the order of AAAA, AABB (SP-A), ABAB (SP-B), AABB (SP-B), and ABAB (SP-B). (excitation condition: 400 Arms, 200 Hz): (a) $\mathrm{SPP}=2 ;$ (b) $\mathrm{SPP}=3$; (c) $\mathrm{SPP}=4$ (bars with dark colors: $1 \mathrm{D}$ analytical results, bars with light colors: FE results).

The results in Figure 10 indicate that the 1D analytical model shows acceptable errors in AC loss estimation when compared to the FE model, despite the differences between the two models. In particular, a comparison of the two results showed very similar trends with almost constant offsets. This indicated that the analytical tool can be used for screening purposes in the early design stage if the predicted trends are as good as those obtained via FE analysis. The major sources of offset error, as previously mentioned, are the combined effects of core saturation, rotor MMF, and rotor rotation.

\section{Analysis of AC Loss via Practical FE Models}

\subsection{Design Parameters and Simulation Conditions}

Owing to the nature of the 1D problem, the ideal model introduced in Section 2 shows several differences from the IPM machines used in production EVs. Although the core saturation and rotor effects are included in the FE analysis in Section 2.3, there are other features that must be included for a complete study. For example, typical commercial IPM machines exhibit additional spacing within the slot owing to the winding insulation. Furthermore, most commercial IPM machines adopt semi-closed slot openings to mitigate torque ripple. Hence, including the effects of winding insulation and slot opening can lead to a difference in estimating the AC losses because they affect the average torque and field variations within the slot. This section discusses the results of a study that reflects these practical issues. Additionally, the AC losses in the end winding region were calculated by analytically modeling the geometry of the end winding.

By considering an example of an IPM machine with three SPP values, six conductors, and a full-pitch winding arrangement, a cross-sectional view of the machine is shown in Figure 11. The model contains gaps due to insulation materials and semi-closed slot openings. Table 3 lists the design parameters of the IPM machine example. The remaining baseline IPM machines with different SPP values and number of layers are designed to reflect the same performance requirements listed in Table 3 and design constraints introduced in Section 2.3. 


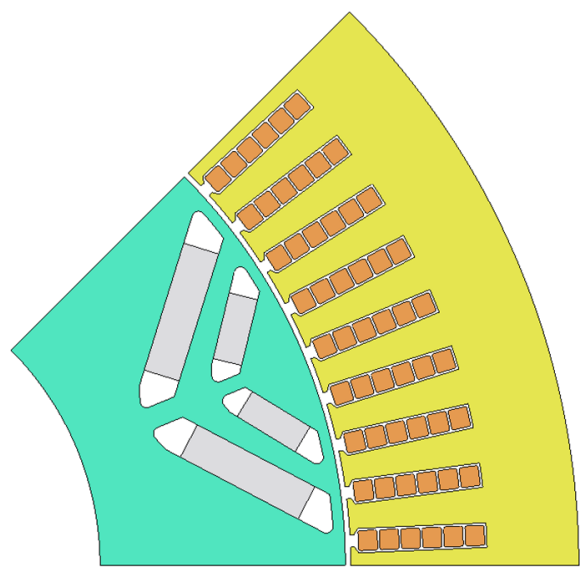

Figure 11. Cross section of the IPM model with three SPP values and six conductors.

Table 3. Design parameters for the baseline IPM machines.

\begin{tabular}{cc}
\hline Design Parameter & Value \\
\hline Peak Power & $98 \mathrm{~kW}$ \\
Peak Torque at 400 Arms & $290 \mathrm{Nm}$ \\
Max Speed & $15,000 \mathrm{rpm}$ \\
Rotor Diameter & $150 \mathrm{~mm}$ \\
Airgap Length & $0.73 \mathrm{~mm}$ \\
Average Insulation Thickness & $0.30 \mathrm{~mm}$ \\
Back Iron Thickness & $12.50 \mathrm{~mm}$ \\
Magnet Material & NMX-36EH (Hitachi) \\
Magnet Remanence at $100{ }^{\circ} \mathrm{C}$ & $1.1 \mathrm{~T}$ \\
Lamination Steel & $35 \mathrm{JN} 300$ (JFE)
\end{tabular}

\subsection{End Winding AC Losses}

Until now, only in-slot AC losses were calculated using the analytical model and FE analysis, and the losses in the end winding region were ignored for simplicity. However, it is not unusual for the end winding to consume as high as $50 \%$ of the entire stator winding. Therefore, the AC losses in the end winding must be considered to present a complete analysis of winding loss. A diamond-shaped coil is assumed to calculate the length of the end winding, as shown in Figure 12.

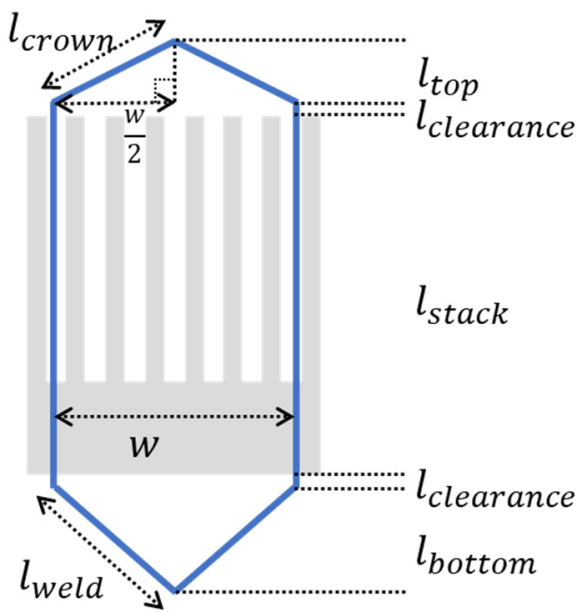

Figure 12. Diamond coil geometry. 
Figure 12 shows the geometry of the diamond-shape coil. The width of an individual winding pin, $w$, is determined by the coil pitch and number of slots, which can be expressed as follows:

$$
w=2 \pi r_{\text {mid }} \frac{\text { coil pitch }}{\text { number of slots }}
$$

where $r_{\text {mid }}$ is the distance from the center of the machine to the center of the slot.

The length of the crown-side end winding and weld-side end winding, $l_{\text {crown }}$ and $l_{\text {weld }}$, can be calculated as in the following:

$$
\begin{aligned}
& l_{\text {crown }}=\sqrt{\left(\frac{w}{2}\right)^{2}+\left(l_{\text {top }}\right)^{2}} \\
& l_{\text {weld }}=\sqrt{\left(\frac{w}{2}\right)^{2}+\left(l_{\text {bottom }}\right)^{2}}
\end{aligned}
$$

where $l_{\text {top }}$ is the distance from the end of the core to the end of the crown-side end winding, $l_{\text {bottom }}$ is the distance from the end of the core to the end of the weld-side end winding.

Finally, the total length of the diamond coil, l_total, can be calculated as follows:

$$
l_{\text {total }}=2 l_{\text {stack }}+4 l_{\text {clearnace }}+2 l_{\text {crown }}+2 l_{\text {weld }}
$$

Assuming a clearance gap, $l_{\text {clearance }}$, of $3 \mathrm{~mm}, l_{\text {top }}$ equals $22 \mathrm{~mm}$ and $l_{\text {bottom }}$ equals $31 \mathrm{~mm}$ for the design shown in Figure 12. Once total length is determined, total AC losses can be calculated via FE analysis, assuming end windings are straight bars in the air.

\subsection{Simulation Results of the Practical IPM Machines}

To comprehensively understand the AC loss characteristics of the baseline IPM machines as a function of the machine performance, total mass, and material cost, an index for the total winding losses per torque density (LPTD, unit: $\mathrm{W} /(\mathrm{Nm} / \mathrm{kg})$ ) was used. The amount of rotor magnet contents, which is the most dominant cost component, remains constant in the baseline designs owing to the same rotor constraint. Hence, the cost of a machine remains proportional to the torque density metric under the given constraints. Consequently, the LPTD index can be used to represent a machine's performance in terms of torque, mass, and cost.

Figure 13a presents a comparison of the LPTD values for the baseline machines, including the end winding losses for peak torque conditions at $200 \mathrm{~Hz}$. Figure $13 \mathrm{~b}$ shows a comparison of the $\mathrm{AC}$ losses in Watt for the baseline machines. Interestingly, the results in Figure $13 \mathrm{a}, \mathrm{b}$ are generally consistent with each other except for the two SP-B configurations. This implies that the LPTD metric decreases as the number of layers and in-slot phase number increase. The design with an SPP value of 2 exhibits much higher LPTD values when compared to those with SPP values other than 2 irrespective of the number of layers and phase arrangement. The lowest LPTD values occur when the stator windings adopt SP-A configuration with eight conductors per slot. LPTD values are higher for the SP-B configurations, owing to their lower winding factor. Figure 14 shows that the reduced winding factor increases the total mass of the machines with the SP-A configuration. 


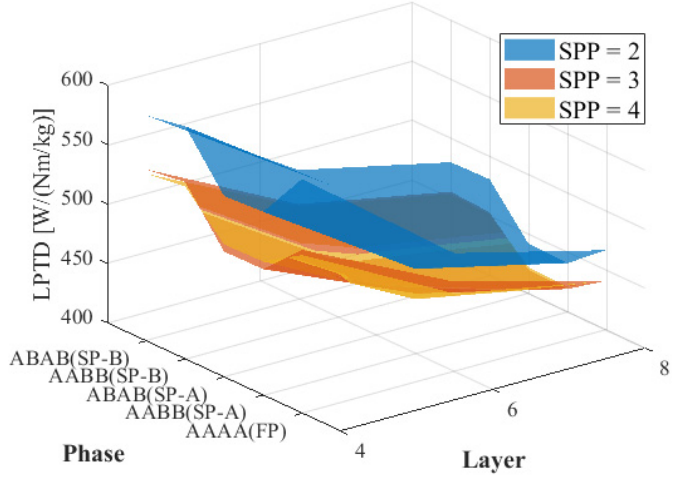

(a)

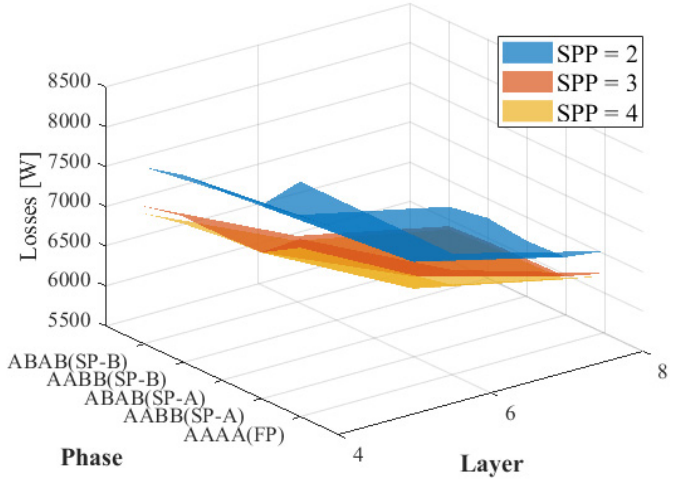

(b)

Figure 13. Comparison of FE-calculated LPTD values and total AC losses for the baseline IPM machines as a function of phase arrangement and number of layers for three SPP values (excitation condition: 400 Arms at $200 \mathrm{~Hz}$ ): (a) LPTD values; (b) Total losses.

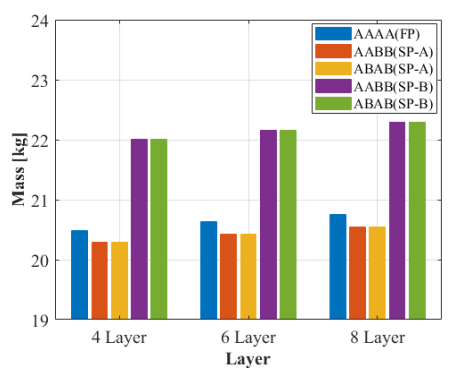

(a)

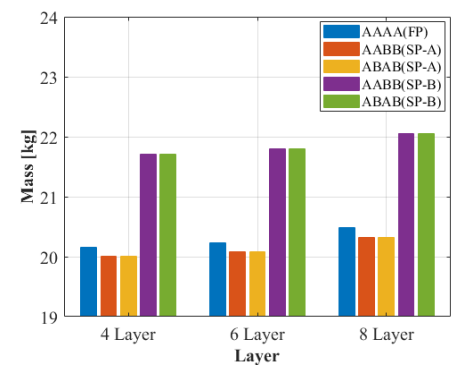

(b)

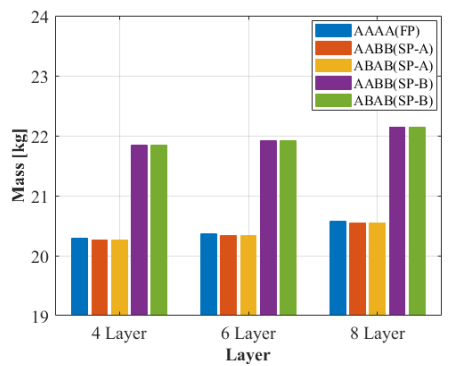

(c)

Figure 14. Comparison of the total mass of the baseline designs as a function of SPP, layer, phase arrangements, and winding layout: (a) $\mathrm{SPP}=2$; (b) $\mathrm{SPP}=3$; (c) $\mathrm{SPP}=4$.

\section{AC Loss Analysis at Peak Power and Partial Load Conditions}

In addition to the loss calculations performed for a single operating point, it is important to calculate the average loss over a vehicle driving cycle to complete the design of a traction machine. However, these types of calculations require a significant amount of time using the FE analysis. An alternative method of using selected key operating points was introduced [14]. Among the several important operating conditions, high-speed and light-load conditions are known to be crucial for vehicle fuel economy. In this study, partial load conditions with $20 \%$ of peak torque, from 2000 to $15,000 \mathrm{rpm}$, were selected for the AC loss analysis of the baseline IPM machines.

In addition to the representative operating points for fuel economy, peak power operation is essential from the perspective of EV performance. Two operating conditions at low and high speeds were selected to investigate the AC losses of the baseline IPM machines during peak power operation. Figure 15 shows the selected operating conditions at partial loads (see yellow diamonds) and peak power conditions (green circles). 


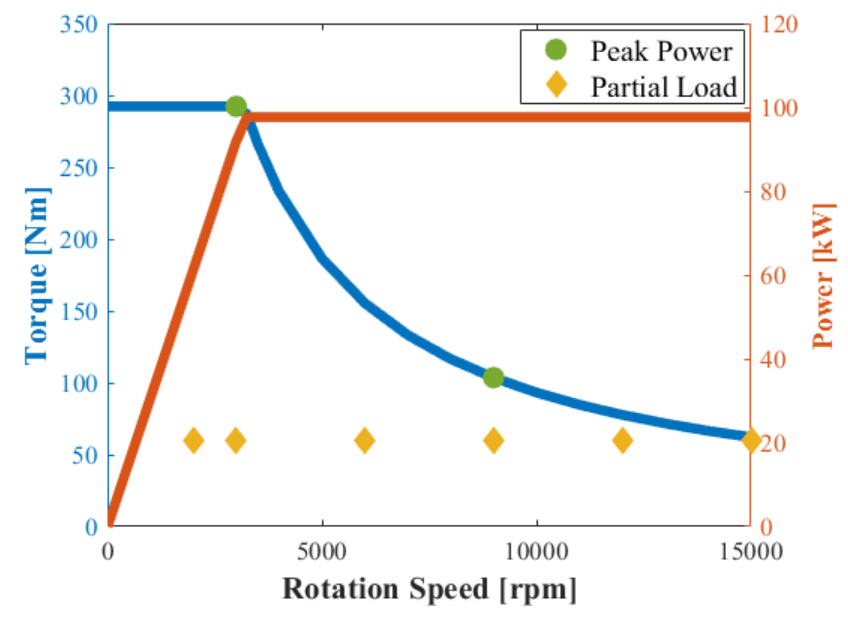

Figure 15. Torque/power-speed curves overlaid with the selected key operating points at peak power and partial load.

\subsection{Peak Power Operation}

Table 4 lists the magnitude and phase angle of the phase currents at the peak power for two different speeds, $3000 \mathrm{rpm}$ and $9000 \mathrm{rpm}$. The results in the table indicate that the current magnitude decreases and phase angle increases in the high-speed, flux-weakening operation region. Figure 16 presents a comparison of the LPTD values at peak power for 3000 and $9000 \mathrm{rpm}$. As shown, the LPTD values of the three IPM machines are similar at $3000 \mathrm{rpm}$, where DC losses are dominant. However, the total copper losses increased drastically at $9000 \mathrm{rpm}$, specifically for the machine with two SPP values. This implies that the skin and proximity effects become increasingly important at this high speed. The results are similar to the previous results, wherein the AC losses increase with an increasing number of conductors. The lowest losses occur when an ABAB type of winding arrangement with eight conductors is adopted.

Table 4. Current magnitude and phase (gamma) angle at peak power for two speeds.

\begin{tabular}{ccc}
\hline Speed [rpm] & Current Magnitude [Arms] & Gamma Angle $\left.{ }^{\circ}{ }^{\circ}\right]^{-}$ \\
\hline 3000 & 400 & 55 \\
9000 & 209.7 & 73.2 \\
\hline
\end{tabular}

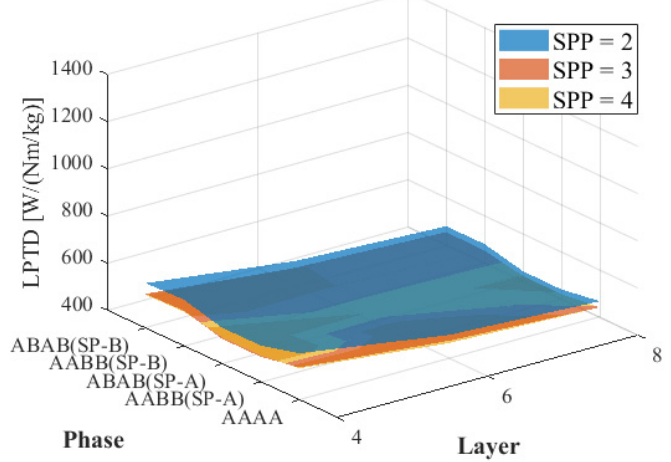

(a)

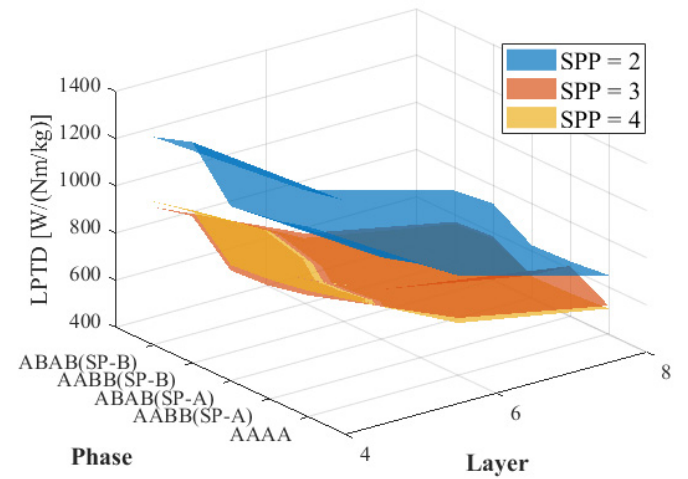

(b)

Figure 16. Comparison of LPTD as a function of phase arrangement and conductor layer for three SPP values: (a) $98 \mathrm{~kW}$ at $3000 \mathrm{rpm}$; (b) $98 \mathrm{~kW}$ at $9000 \mathrm{rpm}$. 


\subsection{Partial Load Operation}

Table 5 lists the magnitude and phase angle of the phase currents at $20 \%$ of the peak torque for speeds ranging from $2000 \mathrm{rpm}$ to $15,000 \mathrm{rpm}$. The results in the table show that the current magnitude and phase angle increase as speed increases under the partial load condition.

Table 5. Current magnitude and phase (gamma) angle at $20 \%$ peak torque for six speeds.

\begin{tabular}{ccc}
\hline Speed [rpm] & Current Magnitude [Arms] & Gamma Angle ${ }^{\circ}{ }^{{ }^{\prime}}$ \\
\hline 2000 & 87 & 31.3 \\
3000 & 87 & 31.3 \\
6000 & 87 & 31.3 \\
9000 & 116 & 64.5 \\
12,000 & 155 & 75.3 \\
15,000 & 196 & 80.1 \\
\hline
\end{tabular}

Figure 17 shows a comparison of the LPTD of the baseline IPM machines for speeds ranging from 3000 to $9000 \mathrm{rpm}$ under $20 \%$ of the peak torque condition. The results are similar to those in Figure 16. The results show a slight difference in the LPTD at low speeds between the baseline machines. However, the AC losses rapidly increase as the speed increases. This becomes more pronounced as the number of layers decreases. Additionally, irrespective of the number of layers and SPP, the lowest LPTD always occurs for the designs with SP-A (ABAB type) arrangement. Thus, as mentioned earlier, the worst-case losses occur when SPP equals 2 . This can be due to the relatively large cross-sectional area of the bar windings of the machine with 2 SPP. Interestingly, the LTPD values were very similar for both 3 SPP and 4 SPP, which is likely because the fill factor decreases as SPP increases.

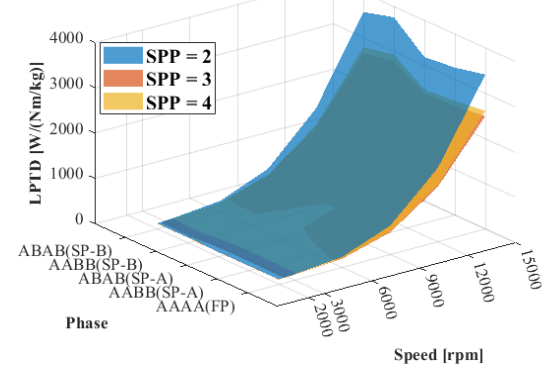

(a)

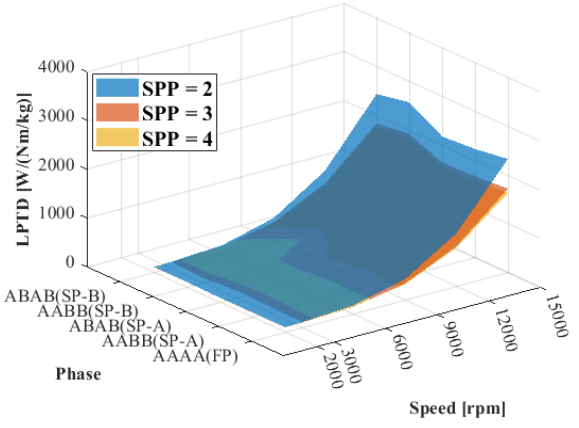

(b)

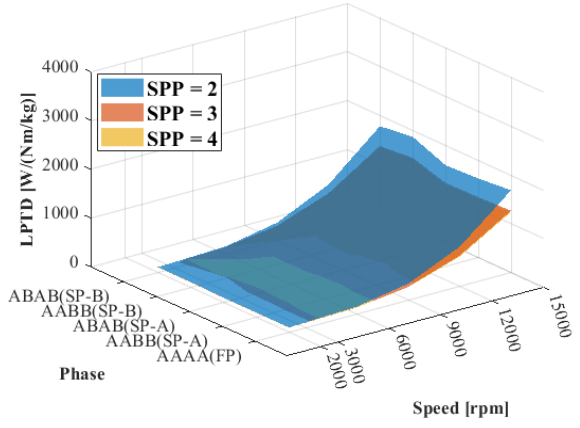

(c)

Figure 17. Comparison of LPTD under $20 \%$ of peak torque condition as a function of phase arrangement and speed for three SPP values: (a) four conductors; (b) six conductors; (c) eight conductors.

To date, FE simulation results suggest that the total AC losses decrease as the number of layers and SPP values increase. However, manufacturing complexity and cost also increase if the number of individual hairpin windings is excessively high. Figure 18 shows the number of hairpin windings required to manufacture the windings of an entire stator as a function of SPP values and number of layers. As expected, the number of total winding pins increases linearly as the number of layers and SPP values increase. 


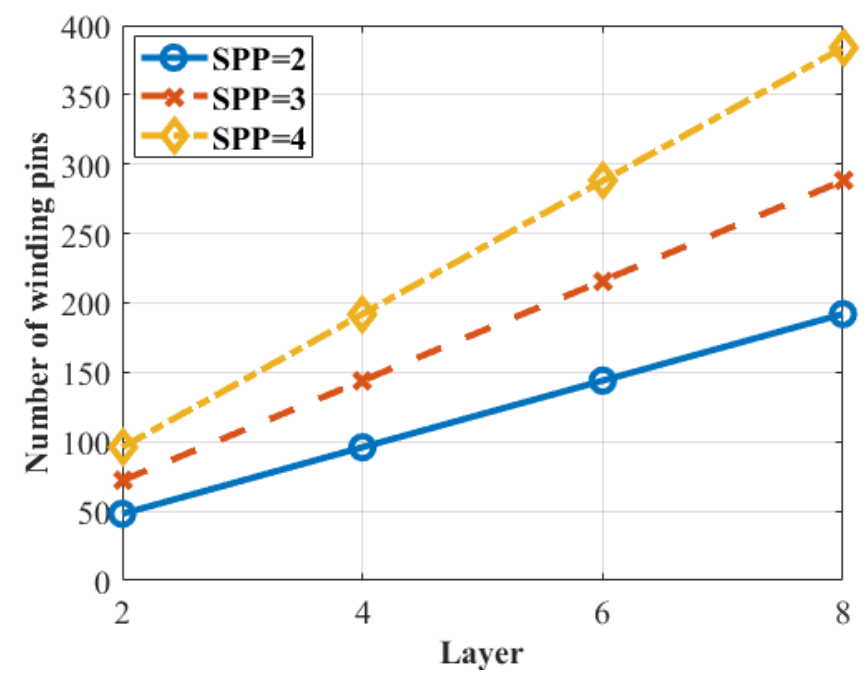

Figure 18. Total number of hairpin windings as a function of SPP value and number of conductor layers.

Finally, the AC losses of the baseline machines can be reduced further if the machines are fully optimized using multi-objective, multi-variable optimization algorithms [35-37].

\section{Discussion and Conclusions}

In this study, an analytical model was developed and verified via FE analysis to investigate the effect of motor design parameters on AC winding losses. The primary observations using the analytical model include the following:

- AC winding losses generally increase as the number of layers and phases increase within the slot.

- $\quad$ Conductor height $d$ significantly impacts AC winding losses, and its effect becomes increasingly important as the conductor height deviates from the optimal ratio, $\delta_{\text {optimal }}$, considering the skin effect.

- $\quad$ Conversely, conductor width $W_{w}$ primarily affects the DC winding losses as opposed to AC losses.

- In general, the SPP values are inversely proportional to the AC losses when constrained by the same conductor aspect ratio and the same MMF constraints.

The AC loss characteristics of practical IPM machines were investigated using LPTD as a key performance metric. To ensure a fair comparison, baseline traction machines are designed based on the same specifications and constraints. The major observations are as follows:

- By changing the winding layout, AC losses can be effectively reduced, albeit at the cost of average torque degradation.

- Changes in phase arrangement leads to relatively low impact on the LPTD

- Worst-case losses occur for the machines with SPP value of 2.

- Conversely, a similar level of AC losses occurs for 3 SPP and 4 SPP machines, regardless of the number of layers and winding layout.

Unfortunately, no experimental verification is included in this study owing to the limited funding for this study. The construction of a full-scale prototype machine and experimental segregation of AC winding losses for verification purposes are considered highly challenging from financial and technical perspectives. Our future plans involve experimental verification as well as optimization for the results presented in this study.

Finally, it should be emphasized that the generalization of all observations and conclusions presented in this study can lead to inaccurate or inappropriate decisions. Hence, it is the designer's responsibility to carefully select the type of winding configuration based on the specific application requirements when designing a traction machine with hairpin windings. 
Author Contributions: Methodology, software, formal analysis, validation, data curation, writingoriginal draft preparation, M.C.; conceptualization, methodology, formal analysis, writing-review and editing, supervision, G.C. All authors have read and agreed to the published version of the manuscript.

Funding: This work was supported in part by Inha University Research Grant and by the National Research Foundation of Korea (NRF) grant funded by the Korea government (MSIP) (No. 2021R1F1A1048754).

Institutional Review Board Statement: Not applicable.

Informed Consent Statement: Not applicable.

Data Availability Statement: Not applicable.

Conflicts of Interest: The authors declare no conflict of interest.

\section{References}

1. Kong, H. Electric Vehicle Development: The Past, Present \& Future. In Proceedings of the International Conference on Power Electronics Systems and Applications (PESA 2009), Hong Kong, China, 20-22 May 2009; pp. 1-3.

2. Raihan, M.A.H.; Smith, K.J.; Almoraya, A.A.; Khan, F. Interior Permanent Magnet Synchronous Machine (IPMSM) Design for Environment Friendly Hybrid Electric Vehicle (HEV) Applications. In Proceedings of the IEEE Region 10 Humanitarian Technology Conference (R10-HTC 2017), Dhaka, Bangladesh, 21-23 December 2017; pp. 1-4.

3. Berardi, G.; Nategh, S.; Bianchi, N.; Thioliere, Y. A Comparison between Random and Hairpin Winding in E-mobility Applications. In Proceedings of the Annual Conference of the IEEE Industrial Electronics Society (IECON), Singapore, 18-21 October 2020; pp. $815-820$.

4. Berardi, G.; Bianchi, N. Design Guideline of an AC Hairpin Winding. In Proceedings of the International Conference on Electrical Machines (ICEM 2018), Alexandroupoli, Greece, 3-6 September 2018; pp. 1-7.

5. Arzillo, A. Challenges and Future Opportunities of Hairpin Technologies. In Proceedings of the International Symposium on Industrial Electronics (ISIE 2020), Delft, The Netherlands, 17-19 June 2020; pp. 1-6.

6. Jung, D.S.; Kim, Y.H.; Lee, U.H.; Lee, H.D. Optimum Design of the Electric Vehicle Traction Motor using the Hairpin Winding. In Proceedings of the IEEE 75th Vehicular Technology Conference (VTC 2012), Yokohama, Japan, 6-9 May 2012; pp. 1-4.

7. Ha, T.; Han, N.G.; Kim, M.S. Experimental Study on Behavior of Coolants, Particularly the Oil-Cooling Method, in Electric Vehicle Motors Using Hairpin Winding. Energies 2021, 14, 956. [CrossRef]

8. Liu, C. Experimental Investigation on Oil Spray Cooling with Hairpin Windings. IEEE Trans. Ind. Electron. 2020, 67, 7343-7353. [CrossRef]

9. Aoyama, M.; Deng, J. Visualization and Quantitative Evaluation of Eddy Current Losses in Bar-Wound Type Permanent Magnet Synchronous Motor for Mild-Hybrid Vehicles. CES Trans. Electr. Mach. Syst. 2019, 3, 269-278. [CrossRef]

10. Gerling, D. Approximate Analytical Calculation of the Skin Effect in Rectangular Wires. In Proceedings of the International Conference on Electrical Machines (ICEM 2009), Tokyo, Japan, 15-18 November 2009; pp. 1-6.

11. Reddy, P.B.; Jahns, T.M.; Bohn, T.P. Transposition Effects on Bundle Proximity Losses in High-Speed PM Machines. In Proceedings of the IEEE Energy Conversion Congress and Exposition (ECCE 2009), San Jose, CA, USA, 20-24 September 2009; pp. 1919-1926.

12. Gonzalez, D.A.; Saban, D.M. Study of the Copper Losses in a High-Speed Permanent-Magnet Machine with Form-Wound Windings. IEEE Trans. Ind. Electron. 2014, 61, 3038-3045. [CrossRef]

13. Mellor, P.H.; Wrobel, R.; McNeill, N. Investigation of Proximity Losses in a High Speed Brushless Permanent Magnet Motor. In Proceedings of the IEEE Industry Applications Society (IAS 2006), Tampa, FL, USA, 8-12 October 2006; pp. $1514-1518$.

14. Momen, F.; Rahman, K.; Son, Y. Electrical Propulsion System Design of Chevrolet Bolt Battery Electric Vehicle. IEEE Trans. Ind. Appl. 2019, 55, 376-384. [CrossRef]

15. Zhao, Y.; Li, D.; Pei, T.; Qu, R. Overview of the Rectangular Wire Windings AC Electrical Machine. CES Trans. Electr. Mach. Syst. 2019, 3, 160-169. [CrossRef]

16. Bianchi, N.; Berardi, G. Analytical Approach to Design Hairpin Windings in High Performance Electric Vehicle Motors. In Proceedings of the Energy Conversion Congress and Exposition (ECCE 2018), Portland, OR, USA, 23-27 September 2018; pp. 1-8.

17. Preci, E. Hairpin Windings: Sensitivity Analysis and Guidelines to Reduce AC Losses. In Proceedings of the IEEE Workshop on Electrical Machines Design, Control and Diagnosis (WEMDCD 2021), Modena, Italy, 8-9 April 2021; pp. 82-87.

18. Xue, S.; Michon, M. Optimisation of Hairpin Winding in Electric Traction Motor Applications. In Proceedings of the IEEE International Electric Machines \& Drives Conference (IEMDC 2021), Hartford, CT, USA, 17-20 May 2021; pp. 1-7.

19. Khang, H.V.; Arkkio, A.; Saari, J. Loss Minimization for Form-Wound Stator Winding of a High-Speed Induction Motor. IEEE Trans. Magn. 2012, 48, 4874-4879. [CrossRef]

20. Zhang, W.; Jahns, T.M. Analytical 2-D Slot Model for Predicting AC Losses in Bar-Wound Machine Windings due to Armature Reaction. In Proceedings of the 2014 IEEE Transportation Electrification Conference and Expo (ITEC), Dearborn, MI, USA, 15-18 July 2014; pp. 1-6. 
21. Mukherjee, S.; Gao, Y.; Maksimovic, D. Reduction of AC Winding Losses Due to Fringing-Field Effects in High-Frequency Inductors with Orthogonal Air Gaps. IEEE Trans. Power Electron. 2021, 36, 815-828. [CrossRef]

22. Islam, M.S.; Husain, I. Asymmetric Bar Winding for High-Speed Traction Electric Machines. IEEE Trans Transp. Electrif. 2020, 6, 3-15. [CrossRef]

23. Wang, Y.; Pries, J. Computationally Efficient AC Resistance Model for Stator Winding with Rectangular Conductors. IEEE Trans Magn. 2020, 56, 8100509. [CrossRef]

24. Zhang, W.; Jahns, T.M. Analytical Model for Predicting AC Losses in Form-Wound Machine Windings due to Stator Current Interactions. In Proceedings of the IEEE International Electric Machines and Drives Conference (IEMDC 2015), Coeur d'Alene, ID, USA, 10-13 May 2015; pp. 1131-1137.

25. Zhang, W. Winding Losses in High-Speed Machines using Form-Wound Windings. Ph.D. Thesis, University of Wisconsin, Madison, WI, USA, 2015.

26. Mellor, P.; Wrobel, R. AC Losses in High Frequency Electrical Machine Windings Formed from Large Section Conductors. In Proceedings of the IEEE Energy Conversion Congress and Exposition (ECCE 2014), Pittsburgh, PA, USA, 14-18 September 2014; pp. 5563-5570.

27. Perry, M.P. Multiple Layer Series Connected Winding Design for Minimum Losses. IEEE Trans Power Appar. Syst. 1979, 98, 116-123. [CrossRef]

28. Sullivan, C.R. Computationally Efficient Winding Loss Calculation with Multiple Windings, Arbitrary Waveforms, and TwoDimensional or Three-Dimensional Field Geometry. IEEE Trans. Power Electron. 2001, 16, 142-150. [CrossRef]

29. Arzillo, A. An analytical Approach for the Design of Innovative Hairpin Winding Layouts. In Proceedings of the International Conference on Electrical Machines (ICEM 2020), Gothenburg, Sweden, 23-26 August 2020; pp. 1534-1539.

30. Li, K.; Cheng, G. Performance Optimization Design and Analysis of Bearingless Induction Motor with Different Magnetic Slot Wedges. Results Phys. 2019, 12, 349-356. [CrossRef]

31. Xiao, Y.; Zhou, L. Design and Performance Analysis of Magnetic Slot Wedge Application in Double-Fed Asynchronous MotorGenerator by Finite Element Method. IET Electr. Power Appl. 2018, 12, 1040-1047.

32. Stoll, R. The Analysis of Eddy Currents; University of Oxford: Oxford, UK, 1974.

33. Lipo, T.A. Introduction to AC Machine Design; University of Wisconsin: Madison, WI, USA, 2017.

34. Dale, M.E.; Sullivan, C.R. Comparison of Single-Layer and Multi-Layer Windings with Physical Constraints or Strong Harmonics. In Proceedings of the IEEE International Symposium on Industrial Electronics (ISIE 2006), Montreal, QC, Canada, 9-13 July 2006; pp. 1467-1473.

35. Sun, X.; Shi, Z.; Lei, G.; Guo, Y.; Zhu, J. Multi-Objective Design Optimization of an IPMSM Based on Multilevel Strategy. IEEE Trans. Ind. Electron. 2021, 68, 139-148. [CrossRef]

36. Sun, X.; Shi, Z.; Zhu, J. Multiobjective Design Optimization of an IPMSM for EVs Based on Fuzzy Method and Sequential Taguchi Method. IEEE Trans. Ind. Electron. 2021, 68, 10592-10600. [CrossRef]

37. Lee, J.H.; Kim, J.W.; Song, J.Y.; Kim, D.W.; Kim, Y.J.; Jung, S.Y. Distance-Based Intelligent Particle Swarm Optimization for Optimal Design of Permanent Magnet Synchronous Machine. IEEE Trans. Magn. 2017, 53, 7206804. [CrossRef] 